\title{
SPONTANEOUS PNEUMOTHORAX IN SCLERODERMA
}

\author{
BY \\ M. S. ISRAEL AND B. J. S. HARLEY \\ From the Royal Hospita!, Wolverhampton
}

(RECEIVID FOR PUBLICATION OCTOBER 28, 1955)

Though the association between pulmonary fibrosis and scleroderma has been recognized for over 60 years (Finlay, 1891), it is only within the last decade that cyst formation has been recognized as a possible part of the lung condition, following the detailed description by Getzowa (1945) of the morbid anatomy and histology of two fatal cases.

Since then a considerable literature has arisen. Some of the cases reported were diagnosed only on radiological grounds (Church and Ellis, 1950; Hayman and Hunt, 1952; Ellman and Cudcowicz, 1954; Dawson, 1955), but others have been confirmed at necropsy (Spain and Thomas, 1950; Aronson and Wallerstein, 1950; Evans and Parker, 1954).

We are adding the following case to the literature because it appears to be the first described in which this cystic element presented itself clinically by the production of a fatal spontaneous pneumothorax.

\section{CASE REPORT}

A housewife, aged 62 years, was admitted on Nay 26, 1954 , to the Royal Hospital, Wolverhampton, under the care of Dr. J. H. Sheldon. Her main complaints were progressive shortness of breath on exertion and an unproductive cough, both of which had been present for six years. She had been examined at a chest clinic shortly after the onset of her symptoms and was told that her chest radiograph was clear. Eighteen months later she noticed that her face was becoming thin and pinched, and three years after her initial symptoms her fingers became stiff and occasionally "dead and blue." The pulps swelled up and discharged chalky material intermittently. Throughout this period she was aware of increasing lassitude and weakness. There was no complaint of dysphagia or dyspepsia at any time.

On examination the patient was found to be a very thin woman with typical advanced sclerodermatous changes involving the skin of the face and hands. The thickened, inelastic skin around the mouth restricted its gape, and the contracture of the skin of the hands and forearms produced crippling and flexion deformity of the wrists and fingers. Diffuse light brown pigmentation was present on the forearms and hands; over the patellar aspects of the knees it was much darker and resembled that of Addison's disease. The pulps of the fingers were enlarged, bulbous and surmounted by pitted scars.
There were numerous crepitations and rhonchi over both lung fields. The blood pressure was $120 / 70 \mathrm{~mm}$. Hg. The rest of the examination revealed no abnormalities.

Special investigations gave the following results:

A blood count gave haemoglobin, $14.8 \mathrm{~g}$. per $100 \mathrm{ml}$; leucocyte count, 5,600 per c.mm. with a normal differential count; erythrocyte sedimentation rate $25 \mathrm{~mm}$. in one hour (Wintrobe). No "L.E." cells were found in the peripheral blood. Total serum proteins $6.6 \mathrm{~g}$. per $100 \mathrm{ml}$. (albumin 3.2, globulin $3.4 \mathrm{~g}$. per $100 \mathrm{ml}$.). Direct examination and culture of sputum for tubercle bacilli yielded negative results on three occasions. Radiography of the finger tips showed calcareous deposits in the soft tissues of the pulp (Fig. 1).

A barium swallow was reported by Dr. A. Booth as showing delay in the passage of barium at the lower end of the oesophagus with some dilatation of the upper oesophagus (Fig. 2).

A chest radiograph showed linear opacities radiating from both hila and cystic appearances towards the periphery (Fig. 3).

A diagnosis of scleroderma with visceral involvement was made, and cortisone was administered in daily doses of $25 \mathrm{mg}$. rising eventually to $37.5 \mathrm{mg}$. She was discharged after a few weeks and seen regularly as an outpatient. The cortisone treatment was continued, and six months later she admitted some symptomatic improvement.

On January 20,1955 , she suddenly experienced extreme shortness of breath and developed pain in the right side of the chest and in the right shoulder. On readmission a week later the clinical and radiological features of a total right-sided pneumothorax were found. A chest radiograph showed two-thirds collapse of the underlying lung (Fig. 4). Her general condition was poor. Though there was no evidence of congestive cardiac failure, she was deeply cyanosed and extremely dyspnoeic. Manometry revealed a tension pneumothorax with mean pressure of more than $+10 \mathrm{~cm}$. of water. Aspiration of $300 \mathrm{ml}$. of air from the pleura produced immediate relief of the dyspnoea. She was given penicillin, 500,000 units six hourly, and the cortisone was continued. Progress appeared to be well maintained, but four days after admission she collapsed quite suddenly and died soon afterwards.

NeCropsy Findings.-A necropsy was performed 30 hours after death. The external features were essentially the same as described above; on incising the 


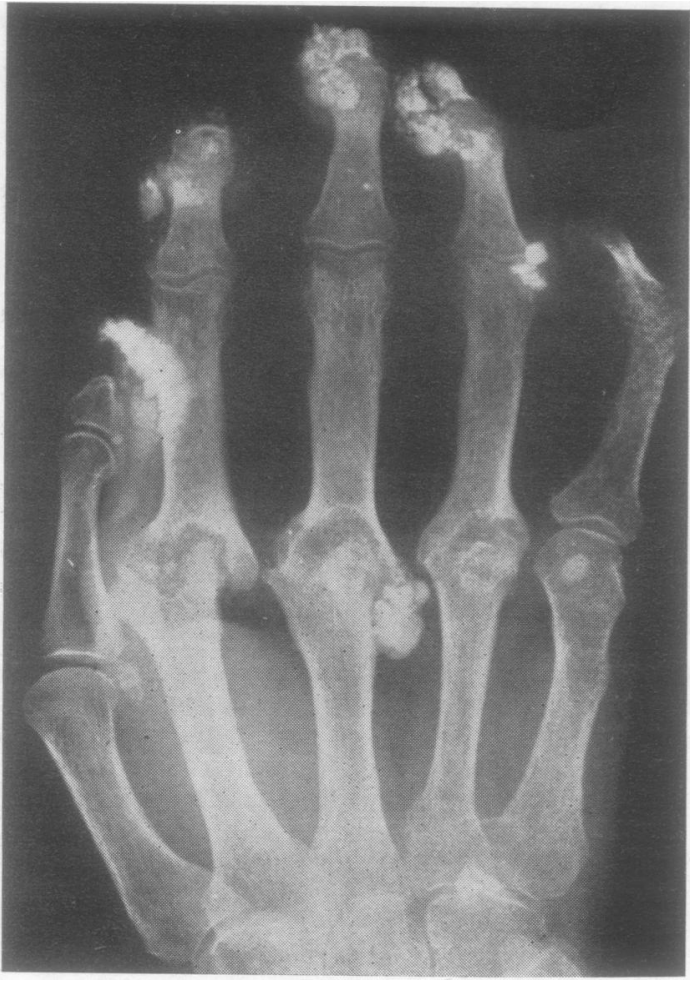

FIG. 1.-Calcareous deposits around finger tips.

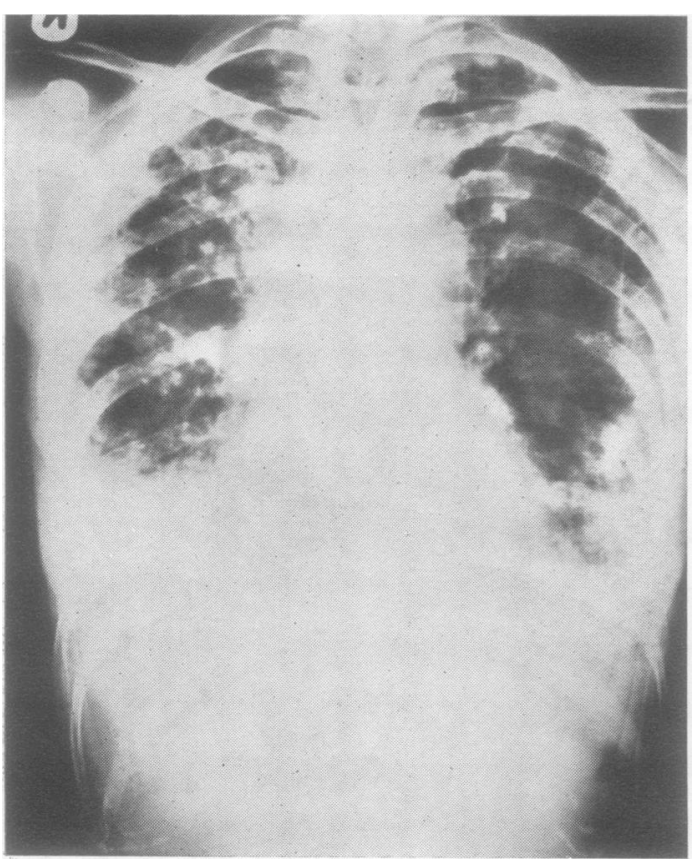

FIG. 3.-Chest radiograph in May, 1954, showing linear opacities radiating from the hila and peripheral cystic areas.



Fig. 2.-Dilated middle and lower oesophagus.



FIG. 4.-Chest radiograph in Jan $13 a r y, 1955$, showing a total rightsided pneumothorax with collapsed, cystic lung underneath. 
finger pulps much gritty, calcareous material escaped. The connective tissue, muscles and joints showed no abnormality. The outstanding changes were pulmonary. The total rtght-sided pneumothorax was confirmed; there were no pleural adhesions on either side. The lungs were small, firm and contracted, this reduction in volume affecting especially the right lung, which was collapsed on account of the superimposed pneumothorax. The visceral pleurae were diffusely thickened, and were surmounted by air-filled bullae which were especially copious under the costal surfaces of the lungs. The cut surfaces of the lungs were clearly divided into a central zone of tough, red pulmonary tissue and a peripheral rind of dense, hard, glistening, fibrous tissue containing innumerable smooth-walled cysts. The peripheral zone was best developed under the costal surfaces of the lungs, but it was present on the medial surfaces also almost up to the hilar attachments. It was thicker around the apices than the bases, and varied in thickness from 0.5 to $3 \mathrm{~cm}$. (Fig. 5).

The cysts varied in diameter from less than $1 \mathrm{~mm}$. to over $3 \mathrm{~cm}$.; the largest were in the right lung. Here a particularly massive one (Fig. 6) with a paper-thin, shiny wall situated subpleurally on the costal surface appeared to be a site of rupture. In its depths were channels communicating with smaller neighbouring cysts, so producing a fine localized meshwork. Apart from this there appeared to be no connexion between individual cysts.

The tissue of the central zone was homogeneous, neither cysts nor fibrotic areas being present. Mucoid material was present in the slightly thickened main bronchi and also in the peripheral cysts. Neither bronchiectasis nor pneumonic change was seen.

The mediastinal lymph nodes were slightly enlarged, firm and pigmented.

The oesophagus was normal. No dilatation, thickening, stenosis or ulceration was present. The rest of the gastro-intestinal tract was also normal. The liver showed moderate chronic venous congestion.



FIG. 5.-Cut surfaces of lungs showing peripheral fibrocystic layer. $\mathbf{L}$

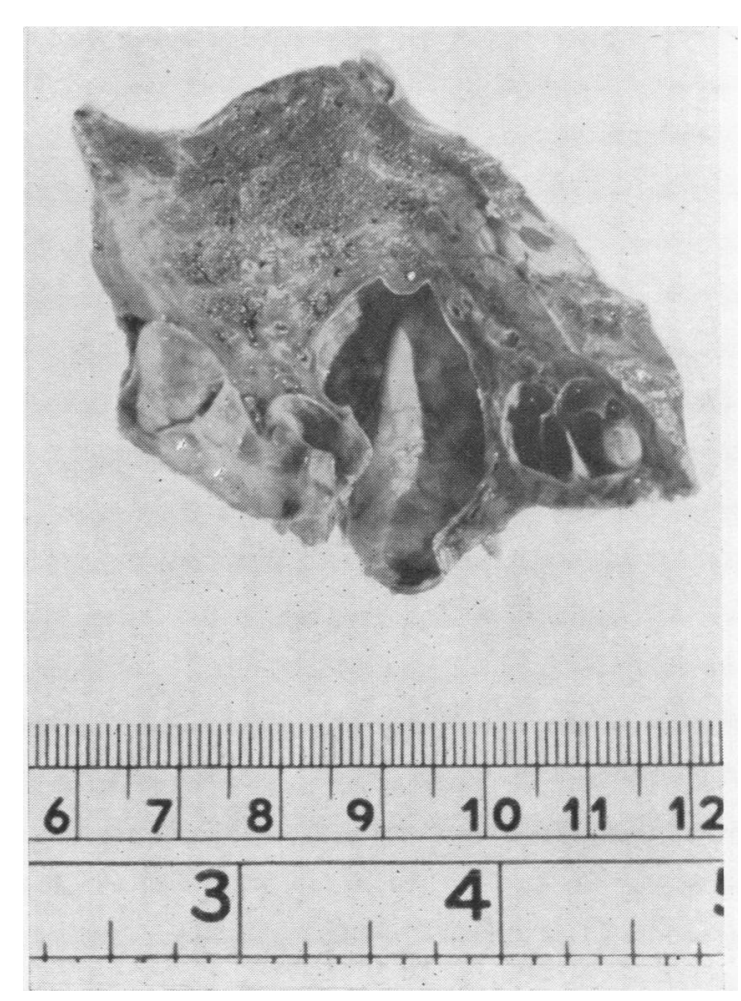

Fig. 6.-Massive ruptured bulla below pleura of right lung $(\times 1 \%)$.

The heart weighed $285 \mathrm{~g}$. Its muscle was the seat of very fine diffuse fibrosis which was most marked in the wall of the left ventricle. The coronary arteries contained minimal deposits of atheroma.

Apart from a mild left-sided, non-obstructive hydrocalicosis and hydronephrosis the genito-urinary system was normal. The other organs likewise showed no abnormality.

Histology.-The skin of the face, hands, and knees had a thinned, atrophic epidermis with excess melanin pigment in the stratum germinativum and also in the dermal melanophores. The dermis was composed of dense, acellular, homogeneous strands of collagen extending down to the subcutaneous tissue and surrounding isolated sweat glands in a fibrous cuff. Elastic fibres were greatly reduced in amount. In the finger pulp, large irregular areas of calcification were present in the fibrotic dermis (Fig. 7). A mild perivascular infiltration of small round cells was seen in the papillary layer only.

The skeletal muscles showed no abnormality.

There was thinning of the muscular coat of the oesophagus and individual muscle fibres were attenuated. There was no notable increase of collagenous tissue in the submucosa, and the muscularis mucosae was normal.

In the heart there was moderate attenuation of the myocardial fibres and a diffuse increase of fibrous tissue among them. 



FIG. 7.-Section of finger pulp showing dense layers of collagen enclosing foci of calcification. (Haematoxylin and eosin, $\times 40$.)

The peripheral zone of the lungs was composed of dense fibrous tissue in which there were many cyst-like spaces (Fig. 8). Some of the largest were lined by an exuberant, columnar ciliated epithelium with numerous goblet cells; their lumina were filled with mucus in which there were very occasional macrophages, and they were surrounded by well-developed layers of smooth muscle and in some cases by cartilaginous bars also. Other smaller spaces had a single layer of low cuboidal epithelium, while some were devoid of any epithelial lining (Fig. 9). These possessed no muscular investment. Some were empty, others contained mucus and many? were filled with foamy macrophages whose cytoplasm $\frac{\bar{\theta}}{\bar{n}}$ stained brilliantly with Scharlach R. There was no $\frac{\bar{s}}{\frac{1}{2}}$ excess of elastic tissue in the fibrous framework, which ${ }_{\propto}^{\mathbb{Q}}$ consisted of dense strands of collagen and was permeated by thin-walled blood vessels of sinusoidal con- $\infty$ figuration. The larger arteries and the arterioles were $\vec{O}$ normal, but the smaller arteries were the seat of moderate $\overrightarrow{-}$ intimal thickening. Small round cells had infiltrated irregularly around some of the cysts. Lymphocytes? predominated, plasma cells were scanty, and polymorphs $\vec{x}$ were absent.

The central zone of the lungs consisted of partially $\vec{\sim}$ collapsed alveoli with thickened, vascular walls. Most -

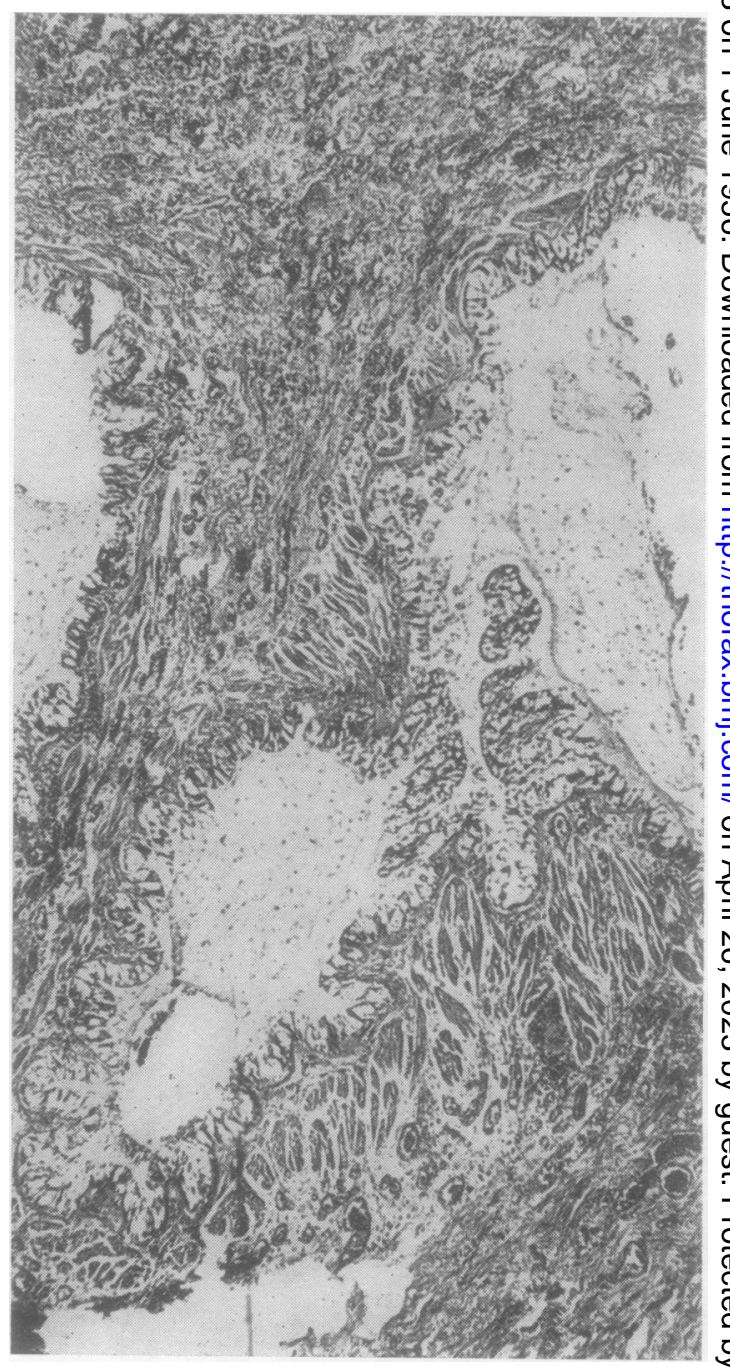

FIG. 8.-Section of periphery of lung showing large cystic space lined by exuberant columnar epithelium and surrounded by layers of smooth muscle. (Haematoxylin and eosin, $\times 40$.) 
of the air spaces were crowded with foamy macrophages whose cytoplasm contained tiny sudanophilic granules. Other alveoli were lined by large, polygonal basophilic cells; these were probably macrophages too. They contained no fat. They tended to coalesce to form syncytial masses, so constituting a definite type of multinucleate giant cell (Fig. 10). Fus cells were not present. Many alveoli in the area adjacent to the peripheral fibrocystic zone had thin, structureless, acellular walls of hyaline appearance. Some had undergone dissolution with the production of large irregular air spaces.

The bronchi were normal. The mediastinal lymph nodes showed non-specific reactive changes only.



FIG. 9.-Smaller cystic spaces without muscular investment and lined by flattened cuboidal epithelium. (Haematoxylin and eosin, $\times 100$.)



FIG. 10.-Alveoli of central area of lung filled with macrophages, some coalescing to form multinucleate giant cells. (Haematoxylin and cosin, $\times 220$.)

The liver showed chronic venous congestion. The endocrine organs were all normal. The venous sinuses of the spleen were dilated and moderately congested; the red pulp was fibrotic. The bone marrow was normal.

\section{Discussion}

Clinically this case is fairly typical, differing from those already described only in the mode of death. The presentation with pulmonary symptoms before the onset of characteristic skin lesions is not unusual: it was noted in seven of the 27 cases of Hayman and Hunt (1952), though four of these had Raynaud's phenomenon beforehand.

The usual cause of death seems to be progressive cachexia associated with dyspnoea and sometimes with symptoms of stomatitis and enteritis (Dostrovsky, 1947; Aronson and Wallerstein, 1950). Spain and Thomas (1950) and Evans and Parker (1954) found severe congestive cardiac failure as well, though the case described by the latter authors was complicated by mitral stenosis.

Spontaneous pneumothorax is a common complication of honeycomb lung (Oswald and Parkinson, 1949), and Evans and Parker (1954) have included scleroderma as one of the causes of this condition. Honeycomb lung is described by Oswald and 
Parkinson (1949) as a variety of cystic disease in which there are thin-walled cysts distributed uniformly throughout the substance of both lungs, and varying in size up to a diameter of $1 \mathrm{~cm}$. By this definition the present case exhibits a very incomplete picture, for the cystic fibrosis is sharply demarcated and specifically peripheral. Indeed, pleural adhesions and fibrosis are often described in scleroderma (Getzowa, 1945; Spain and Thomas, 1950), and pleural thickening has sometimes been indicated radiologically (Lloyd and Tonkin, 1948; Dostrovsky, 1947), though Murphy, Krainin, and Gerson (1941) did succeed in inducing an artificial pneumothorax to demonstrate that the appearances of fibrosis were in fact intrapulmonary. This suggests that the pleural fibrosis in some cases affects only the visceral layer.

Histologically the cystic fibrosis in our case conforms with that previously described. Noteworthy features are the absence of excess elastic tissue unlike the cases reported by Aronson and Wallerstein (1950) and Pagel and Treip (1955), the marked intimal hyperplasia of the small arteries of the fibrous zone, the normal bronchial tree, and the hyalinization and breakdown of the alveolar walls contiguous with the peripheral zone. This last change was especially emphasized by Getzowa (1945), who encountered it over a much wider area of lung tissue.

It seems clear that the large cysts are bronchial or bronchiolar in origin as in the case reported by Evans and Parker (1954); it is probable, as these authors suggest, that they are produced by contraction of the surrounding fibrous tissue. The nature of the smaller cystic spaces, which are devoid of a muscular investment and are lined by a debased cuboidal epithelium, is less certain. Getzowa (1945) regards them as areas of bronchiolar proliferation. It is interesting that these spaces contained lipoid-laden macrophages; this may be suggestive of at least an erstwhile connexion with the alveoli of the central area which were full of these cells.

Alveoli crowded with lipoid-filled macrophages are often found in chronic pulmonary diseases such as bronchiectasis and fibrosis (De Navasquez and Haslewood, 1954); the condition has been given the somewhat pretentious appellation of “endo- $\stackrel{\overrightarrow{\vec{B}}}{\rightarrow}$ genous lipoid pneumonia" (Gross, Brown, and Hatch, 1952). It appears to be quite non-specific. $\frac{\bar{\sigma}}{\bar{D}}$

Both the cardiac and the oesophageal lesions can $\frac{D}{\vec{D}}$ be attributed to scleroderma. The oesophageal $\stackrel{\unrhd}{\varrho}$ dilatation seen radiologically was apparently due to $\%$ atony, for the outstanding pathological feature was $\vec{\circ}$ muscular atrophy without abnormal fibrosis.

\section{SUMmARY}

A case of scleroderma presenting initially with $\stackrel{x}{\vec{x}}$ pulmonary symptoms and succumbing ultimately $\vec{\sim}$ to a fatal spontaneous pneumothorax is described.

The lung lesion was distinctive in type and $\vec{\omega}$ situation: it consisted of a sharply demarcated 을 peripheral zone of cystic fibrosis which encased the entire organ. One particularly large subpleural $c$ cyst had ruptured and produced the pneumothorax. Histologically these larger cysts were bronchial in $\vec{\theta}$ origin.

Other manifestations of scleroderma were diffuse myocardial fibrosis and atrophy of the muscular coat of the oesophagus.

We wish to thank Dr. J. H. Sheldon and Dr. A. G. $\stackrel{2}{\not}$


agement in the clinical and pathological aspects of this $\overrightarrow{\vec{O}}$ case; Dr. Alan Booth for the radiological reports; $\exists$ Professor J. Gough for examining the sections of lung; Professor G. Cunningham for making available the photomicrography facilities of the Royal College of Surgeons of England; and Mr. John Mercer for the photomicrography itself.

\section{REFERENCES}

Aronson, S. M., and Wallerstein, L. (1950). N.Y. St. J. Med., 50, 2723.

Church, R. E., and Ellis, A. R. P. (1950). Lancet, 1, 392

Dawson, J. J. Y. (1955). Proc. roy. Soc. Med., 48, 152.

De Navasquez, S., and Haslewood, G. A. D. (1954). Thorax, 9, 35. 을

Dostrovsky, A. (1947). Arch. Derm. Syph. (Chicago), 55, 1.

Ellman, P., and Cudkowicz, L. (1954). Thorax, 9, 46.

Evans, M., and Parker, R. A. (1954). Ibid., 9, 154.

Finlay, D. W. (1891). Middx. Hosp. Rep., 29.

Getzowa, S. (1945). Arch. Path. (Chicago), 40, 99.
Gross, P., Brown, J. H. U., and Hatch, T. F. (1952). Amer. J. Path., 28, 211 .

Hayman, L. D., and Hunt, R. E. (1952). Dis. Chest, 21, 691.

Lloyd, W. E., and Tonkin, R. D. (1948). Thorax, 3, 241. Lloyd, W. E., and Tonkin, R. D. (1948). Thorax, 3, 241.
Murphy, J. R., Krainin, P., and Gerson, M. J. (1941). J. Amer. med. ${ }^{W}$
Ass., 116, 499.

Oswald, N., and Parkinson, T. (1949). Quart. J. Med., 18, 1.

Pagel, W., and Treip, C. S. (1955). J. clin. Path., 8, 1. 